\title{
Mycobacteria-specific cytokine responses detect TB infection and distinguish latent from active TB
}

Marc Tebruegge ${ }^{1,2,3,4}$, Binita Dutta ${ }^{3}$, Susan Donath ${ }^{1,3,5}$, Nicole Ritz ${ }^{1,2,3,6}$,

Benjamin Forbes ${ }^{3}$, Kattia Camacho-Badilla ${ }^{2}$, Vanessa Clifford ${ }^{1,3}$,

Christel Zufferey $^{3}$, Roy Robins-Browne ${ }^{1,3,7}$, Willem Hanekom ${ }^{8}$,

Stephen M Graham ${ }^{1,3,9}$, Tom Connell ${ }^{1,2,3}$, Nigel Curtis ${ }^{1,2,3}$

${ }^{1}$ Department of Paediatrics, The University of Melbourne, Parkville, Victoria, Australia.

${ }^{2}$ Infectious Diseases Unit, Royal Children's Hospital Melbourne, Parkville, Victoria, Australia.

${ }^{3}$ Murdoch Children's Research Institute, Parkville, Victoria, Australia.

${ }^{4}$ Academic Unit of Clinical \& Experimental Sciences, Faculty of Medicine, University of Southampton, United Kingdom.

${ }^{5}$ Clinical Epidemiology and Biostatistics Unit, Royal Children's Hospital Melbourne, Parkville, Victoria, Australia.

${ }^{6}$ Infectious Diseases Unit, University Children's Hospital Basel, Basel, Switzerland;

${ }^{7}$ Department of Microbiology and Immunology, The University of Melbourne, Parkville, Victoria, Australia.

${ }^{8}$ Institute of Infectious Diseases and Molecular Medicine and School of Child and Adolescent Health, University of Cape Town, Cape Town, South Africa.

${ }^{9}$ Centre for International Child Health, Parkville, Victoria, Australia.

\section{Corresponding author:}

Prof Nigel Curtis, Department of Paediatrics, The University of Melbourne. The Royal Children's Hospital, Flemington Road, Parkville, VIC 3052, Australia. Email: nigel.curtis@rch.org.au. 
Author contributions: Conception and design, M.T., B.D., S.D., N.R., R.R.-B., S.M.G., T.C., and N.C. Acquisition of data, M.T., B.D., B.F., and K.C.-B. Analysis and interpretation of data, M.T., B.D., S.D., N.R., B.F., K.C.-B., V.C., C.Z., R.R.-B., W.H., S.M.G., T.C., and N.C. Drafting the manuscript, M.T. and N.C. Revising the manuscript for important intellectual content: B.D., S.D., N.R., B.F., K.C.-B., V.C., C.Z., R.R.-B., W.H., S.M.G., and T.C.

\section{Potential conflicts of interest:}

All authors - none.

Funding: The study was funded by the Australian National Health and Medical Research Council (NHMRC Project Grant No. 1011200), and received additional support from the John Burge Trust, the Myer Foundation and the Murdoch Children's Research Institute. MT and NR were supported by Fellowship awards from the European Society for Paediatric Infectious Diseases, and by International Research Scholarship awards from The University of Melbourne.

Running head: Cytokine biomarkers of TB infection and disease

Descriptor number: 11.1 (Diagnosis of Tuberculosis or Latent Infection)

Total word count (body of manuscript): 3487 words 


\section{At a glance commentary:}

\section{Scientific knowledge on the subject}

Current immunodiagnostic tests for tuberculosis (TB), including the tuberculin skin test and interferon-gamma release assays (IGRA), have significant limitations. These include the inability to distinguish between latent TB infection (LTBI) and active TB, a distinction that is critical for clinical management.

\section{What this study adds to the field}

This study identified mycobacteria-specific cytokine responses that allow the distinction between TB-infected and TB-uninfected individuals, as well as between LTBI and active TB. Several of the cytokine biomarkers showed better performance characteristics than interferon-gamma, which forms the basis of IGRA. Addition of these biomarkers into future immunodiagnostic assays for TB is likely to result in higher assay sensitivity while retaining high specificity, and could potentially allow the distinction between LTBI and active TB based on a blood test alone. 


\begin{abstract}
Rationale: Current immunodiagnostic tests for tuberculosis (TB), including the tuberculin skin test (TST) and interferon-gamma (IFN- $\gamma$ ) release assays (IGRA), have significant limitations, which include their inability to distinguish between latent TB infection (LTBI) and active TB, a distinction critical for clinical management.
\end{abstract}

Objectives: To identify mycobacteria-specific cytokine biomarkers that characterize TB infection, to determine their diagnostic performance characteristics, and to establish whether these biomarkers can distinguish between LTBI and active TB.

Measurements and main results: 149 children investigated for TB infection were recruited; all participants underwent a TST and QuantiFERON-TB Gold assay. In parallel, whole blood assays using ESAT-6, CFP-10 and PPD as stimulatory antigens were undertaken, and cytokine responses were determined by xMAP multiplex assays. IFN- $\gamma$, IP-10, TNF- $\alpha$, IL-1ra, IL-2, IL-13, and MIP-1 $\beta$ responses were significantly higher in LTBI and active TB cases than in TB-uninfected individuals, irrespective of the stimulant. Receiver operating characteristic analyses showed that IP-10, TNF- $\alpha$, and IL-2 responses achieved high sensitivity and specificity for the distinction between TB-uninfected and TB-infected individuals. TNF- $\alpha$, IL-1ra, and IL-10 responses had the greatest ability to distinguish between LTBI and active TB cases; the combinations of TNF- $\alpha /$ IL-1ra and TNF- $\alpha /$ IL-10 achieved correct classification of $95.5 \%$ and $100 \%$ of cases, respectively.

Conclusions: We identified several mycobacteria-specific cytokine biomarkers with the potential to be exploited for immunodiagnosis. Incorporation of these biomarkers 
into future immunodiagnostic assays for TB could result in substantial gains in sensitivity, and allow the distinction between LTBI and active TB based on a blood test alone.

Abstract word count: 246 words

Keywords: tuberculosis, child, diagnosis, cytokines, assay, biomarker 


\section{INTRODUCTION}

Approximately one third of the world's population is infected with Mycobacterium tuberculosis (MTB), and there are more than 8 million new cases of active TB (ie TB disease) resulting in an estimated 1.3 million deaths each year. ${ }^{1,2}$ Children account for an increasing proportion of TB cases, in both high-resource and low-resource settings. $^{3}$

Despite advances in diagnostics, microbiological confirmation of TB in childhood remains challenging, primarily because most children have paucibacillary disease, reducing the yield of conventional microbiological methods. Newer molecular diagnostic techniques, including the Xpert MTB/RIF assay, show promise, but also perform considerably less well in patients with paucibacillary disease. ${ }^{4}$

Existing immunodiagnostic tests for TB also have considerable limitations. ${ }^{5,6}$ The tuberculin skin test (TST) is operator-dependent and has limited specificity. Falsepositive results can occur as a result of boosting from repeated TST, prior Bacille Calmette-Guérin (BCG) vaccination, or infection with non-tuberculous mycobacteria (NTM). ${ }^{7}$ The comparatively poor specificity of the TST intrinsically results from the use of purified protein derivative (PPD), a heterogeneous mixture of more than 200 mycobacterial peptides, many of which are expressed by BCG vaccine strains and NTM. ${ }^{8}$ Interferon- $\gamma($ IFN- $\gamma$ ) release assays (IGRA), which rely on the detection of IFN- $\gamma$ produced by sensitized T cells, are thought to have better specificity than the TST, as mycobacterial peptides that are absent from all BCG vaccine strains and most NTM are used as the stimulatory antigens in these assays. ${ }^{8}$ Currently licensed IGRA (the QuantiFERON-TB Gold (QFT) assay and the T-SPOT.TB assay) incorporate the 
MTB-specific RD1 peptide antigens early secretory antigenic target 6 (ESAT-6) and $10 \mathrm{kDa}$ culture filtrate protein (CFP-10). However, IGRA have other, important limitations. Although IGRA are solely licensed for the diagnosis of latent TB infection (LTBI), in clinical practice these assays are frequently used to support a presumptive diagnosis of active TB. However, a recent meta-analysis shows that the sensitivity of both commercial IGRA barely exceeds $80 \%$ in patients with active TB. ${ }^{9}$ Furthermore, IGRA perform considerably worse in children, and significant rates of indeterminate results are an additional problem in this age group. ${ }^{10-14}$

A further significant limitation of both TST and IGRA is their inability to discriminate between LTBI and active TB, a distinction that is highly relevant in geographic regions where TB prevalence is high and a large proportion of the population has LTBI. ${ }^{6}$ This distinction is critical, as the treatment of LTBI and active TB differs. Consequently, an immunodiagnostic test that can discriminate between these two infection states would be a major advance for clinical care.

A large body of evidence supports the critical role of IFN- $\gamma$ in the immune response to mycobacterial infections. ${ }^{15,16}$ However, mounting data highlight the importance of other cytokines in the immune response to MTB, which may also have a potential to be used for immunodiagnosis. ${ }^{15-17}$ This study aimed to identify mycobacteria-specific cytokine biomarkers that characterize TB infection, to determine their diagnostic performance characteristics, and to establish whether any of the identified biomarkers can be used to distinguish between LTBI and active TB. 


\section{METHODS}

\section{Participants}

Children and adolescents up to 18 years of age were recruited at the Royal Children's Hospital (RCH) Melbourne between January 2010 and February 2011. Eligible for participation were all children undergoing screening for suspected LTBI or active TB, comprising the following: i) children with symptoms and signs suggestive of active $\mathrm{TB}$, ii) children with known contact with a case of active $T B$, iii) children who had recently migrated from countries with a high TB prevalence (defined by incidence $\geq$ 40 TB cases/100,000 population). The exclusion criteria comprised the following: i) known immunodeficiency, ii) current immunosuppressive treatment (including oral corticosteroids), and iii) TST in the previous 6 to 52 weeks. The last criterion was chosen, because at commencement of the study it was thought that a TST undertaken more than 6 weeks prior to an IGRA may induce boosting, thereby causing a falsepositive IGRA result. ${ }^{18}$ We have subsequently shown this not to be the case. ${ }^{19}$

Prior to participation, informed consent was obtained from the child's parent and/or guardian. The study was approved by the RCH Human Research Ethics Committee (HREC 29040A). Demographics, history and clinical findings were recorded on a standardized data collection sheet. A chest $\mathrm{x}$-ray was obtained in all cases with a positive TST and/or positive IGRA result. Histological, conventional and molecular microbiological tests were performed in all children with suspected active TB as clinically indicated. 


\section{Diagnostic tests}

All participants had a TST placed by specifically-trained nurses by intradermal injection of $0.1 \mathrm{ml}$ of Tubersol (Sanofi Pasteur; Toronto, Canada; bioequivalent to 5 Tuberculin Units PPD-S) into the volar surface of the lower arm, and any resulting induration was recorded after 48 to 72 hours. In addition, blood was obtained for the QFT In-Tube (QFT-GIT) assay, and an additional $10 \mathrm{ml}$ for whole blood assays were collected in heparinized tubes. The QFT-GIT was processed and interpreted at the Victorian Infectious Diseases Reference Laboratories (VIDRL) in accordance with the manufacturer's instructions. Polymerase chain reaction (PCR) testing for M. tuberculosis, for which a Taqman real-time PCR (Applied Biosystems; Waltham, MA) targeting the insertion sequence IS6110 was used, was also performed at VIDRL using previously described methods. ${ }^{20}$

\section{Categorization of participants and definitions}

Participants were categorized into seven categories according to their clinical features, TST, IGRA and microbiological results as detailed in Table 1. Active TB was defined as either i) microbiological confirmation of infection with MTB by culture or polymerase chain reaction (PCR), or ii) a symptomatic patient fulfilling at least two of the following three criteria in conjunction with response to treatment with antituberculous therapy: a) symptoms and signs consistent with active TB (chronic cough, persistent fever, night sweats, unexplained weight loss), b) radiological findings suggestive of active $\mathrm{TB}, \mathrm{c}$ ) presence of risk factors for TB infection (known TB contact, birth or previous residence in a high TB prevalence country). These stringent criteria exceed those proposed by the American Thoracic Society and the Centers for 
Disease Control and Prevention. ${ }^{21}$ In this manuscript, the term 'TB-infected' is used as a collective term for participants with LTBI or active TB.

\section{Whole blood assays}

Whole blood was incubated with ESAT-6, CFP-10 (each at a concentration of $10 \mu \mathrm{g} / \mathrm{ml}$; JPT Peptide Technologies, Berlin, Germany), PPD (20 $\mu \mathrm{g} / \mathrm{ml}$; RT50; Statens Serum Institut, Copenhagen, Denmark), staphylococcal enterotoxin B (SEB) ( $5 \mu \mathrm{g} / \mathrm{ml}$; positive control; Sigma-Aldrich, St. Louis, MO), or without stimulant (negative control) in the presence of co-stimulatory antibodies, anti-CD28 and antiCD49d (each $1 \mu \mathrm{g} / \mathrm{ml}$; BD Biosciences, San Jose, CA). Mycobacterial antigens were added at the beginning of the assay; SEB was only added for the last 5 hours of the incubation period based on previous optimization experiments (data not shown). Following incubation at $37^{\circ} \mathrm{C}$ for 20 to 24 hours, supernatants were harvested and cryopreserved at $-80^{\circ} \mathrm{C}$ for batched analysis.

\section{Cytokine analysis}

Cytokine concentrations in supernatants were measured using Milliplex human cytokine/chemokine kits (Millipore Corp., Billerica, MA) according to the manufacturer's instruction, with analyses conducted on a Luminex 200 analyzer (Luminex Corp., Austin, TX). Based on previous optimization experiments (data not shown), IFN- $\gamma$, tumor necrosis factor-alpha (TNF- $\alpha$ ), IL-1ra, IL-2, IL-10, IL-12(p40), IL-13, IL-15, IL-17, and granulocyte-macrophage colony stimulating factor (GMCSF) were analyzed in undiluted samples with a 10-plex assay, while interferoninducible protein-10 (IP-10), IL-6, IL-8, monocyte chemotactic protein-1 (MCP-1), monocyte chemotactic protein-3 (MCP-3), macrophage inflammatory protein-1-beta 
(MIP-1 $\beta$ ), and CCL5 (RANTES) were analyzed in 1:20 diluted samples with a 7-plex assay. The laboratory scientists performing the sample analysis were blinded to the clinical data and the results of the TST, the QFT-GIT and the microbiological investigations.

\section{Statistical analysis}

Only those participants with an unambiguous diagnosis ('uninfected', 'common discordance', 'LTBI' and 'active TB') were included in the analysis. Participants in the 'probable uninfected' and 'possible discordance' categories were deliberately not included a priori to avoid potential contamination of data.

Comparisons of continuous variables between multiple groups were done using Kruskal Wallis tests. In instances where the Kruskal Wallis p-value was $<0.05$, indicating a difference between the groups, additional two-group comparisons were done using Mann Whitney $U$ tests. Categorical variables were compared using twotailed chi-square tests. A p-value $<0.05$ was considered significant. Cytokine concentrations were background-corrected prior to analysis (ie by subtracting the concentration measured in the negative control sample). Analyses were done using Stata (V11; StataCorp, College Station, TX) and Prism (V5; GraphPad Software Inc., La Jolla, CA). Receiver operating characteristic (ROC) analyses were performed with Prism; the optimal cut-offs for each of the stimulant/cytokine combinations were determined by tabulation of sensitivity against specificity at every threshold in the data set. The study was conducted and is reported in accordance with Quality Assessment of Diagnostic Accuracy Studies (QADAS) criteria. ${ }^{22}$ 


\section{RESULTS}

A total of 149 patients were recruited. Nine participants were excluded: three did not return for TST reading, insufficient blood was obtained in three, a laboratory error occurred during the QFT-GIT processing in one, and the QFT-GIT result was indeterminate in two (both failed positive controls). Therefore, a total of 140 patients were included in the analysis.

The six participants with active TB comprised three patients with microbiologicallyconfirmed TB (one case with intra-thoracic TB; two cases with lymph node TB), and three patients without microbiological confirmation who fulfilled the study criteria for active TB (two cases with pulmonary TB; one case with spinal TB). All six patients had both a positive TST (range: 13 to $25 \mathrm{~mm}$ induration) and a positive QFT-GIT result, as well as resolution of symptoms with anti-tuberculous therapy. Additional patient data are shown in Supplementary Table 1.

Table 2 shows the demographic and other details of the participants in the four major diagnostic categories (uninfected, common discordance, LTBI and active TB). In the remaining three diagnostic categories there were 6 'probable uninfected', 5 'possible discordance' and 4 'reverse discordance' cases.

\section{Mycobacteria-specific cytokine responses in supernatants}

Significant differences in the background-corrected cytokine concentrations measured in supernatants between the four major diagnostic groups in response to all three antigenic stimulants were detected for IFN- $\gamma$, IP-10, TNF- $\alpha$, IL-1ra, IL-2, IL-13, and MIP-1 $\beta$ (Figure 1A-C). Overall, median concentrations of these cytokines were 
highest in the active TB group, followed by the LTBI group. For all seven cytokines the lowest median concentrations were observed in the uninfected group, irrespective of the antigenic stimulant.

Table 3 shows the results of the two-group comparisons of cytokine responses in the four diagnostic groups. Median concentrations of IFN- $\gamma$, IP-10, TNF- $\alpha$, IL-1ra, IL-2, IL-13, and MIP-1 $\beta$ were all significantly higher in the LTBI and the active TB groups, compared with the uninfected group, with all three antigenic stimulants, with the single exception of IL-1ra in PPD-stimulated samples. Most of these comparisons were highly statistically significant with a Mann Whitney $U$ p-value below 0.0001 . In contrast, few comparisons between the LTBI and the active TB group reached statistical significance: TNF- $\alpha$ in ESAT-6- and CFP-10-stimulated samples, IL-1ra in ESAT-6- and PPD-stimulated samples, and IP-10, IL-6 and IL-10 in PPD-stimulated samples. In all instances median concentrations were higher in the active TB group than in the LTBI group (Figure 1), with the exception of IP-10 in PPD-stimulated samples. In addition, a number of significant differences in median cytokine concentrations between the uninfected group and the group with common discordance were detected (Table 3). This was the case not only in response to stimulation with PPD, but also in response to stimulation with ESAT-6 and CFP-10.

\section{Receiver operating characteristic analyses}

To determine the potential for diagnostic use of the seven cytokine responses that were found to have discriminatory ability in the previous analyses, ROC analyses were performed. For this purpose the data from patients with LTBI and active TB were grouped together (TB-infected group; case values), and compared with the data 
from the uninfected group (control values). At their optimal cut-off values, IP-10, TNF- $\alpha$, and IL-2 achieved sensitivity and specificity values close to, or exceeding those of IFN- $\gamma$ (Table 4). The best performance characteristics were observed with IL2 in PPD-stimulated samples (sensitivity: 100\%; specificity: 96\%).

In addition, ROC curves were constructed for each cytokine/stimulant combination (Figure 2). The very high area under curve (AUC) values for IFN- $\gamma$, IP-10, TNF- $\alpha$, and IL-2 (irrespective of the stimulant used) further support the potential of these cytokines to discriminate between TB-uninfected and TB-infected individuals. Notably, the AUC values of IP-10, TNF- $\alpha$ and IL-2 in ESAT-6- and CFP-10stimulated samples universally exceeded those of IFN- $\gamma$.

\section{Ability of cytokine responses to discriminate between LTBI and active TB}

Among the cytokines investigated TNF- $\alpha$, IL-1 ra and IL-10 responses were found to have the greatest ability to discriminate between LTBI and active TB (Figure 3). At a cut-off of $80 \mathrm{pg} / \mathrm{ml}$ in ESAT-6-stimulated samples, and $40 \mathrm{pg} / \mathrm{ml}$ in CFP-10stimulated samples, TNF- $\alpha$ responses correctly classified $81.8 \%$ and $86.4 \%$ of the participants, respectively. In PPD-stimulated samples IL-1ra responses (cut-off: 450 $\mathrm{pg} / \mathrm{ml}$ ) and IL-10 responses (cut-off: $100 \mathrm{pg} / \mathrm{ml}$ ) correctly classified $90.9 \%$ and $100 \%$ of the participants, respectively. Figure 4 shows that combining TNF- $\alpha$ with either of these two cytokines results in very high levels of correct classification. The combination TNF- $\alpha /$ IL-1 ra only classified one participant with LTBI falsely as 'active TB' (95.5\% correct classification); the combination TNF- $\alpha / \mathrm{IL}-10$ classified all participants correctly. 


\section{DISCUSSION}

Our data show that in addition to IFN- $\gamma$, which forms the basis of existing immunodiagnostic tests for TB, several other MTB-specific cytokine responses, namely IP-10, TNF- $\alpha$, IL-1ra, IL-2, IL-13, and MIP-1 $\beta$ responses, differ significantly between individuals infected with MTB and those with no evidence of infection, indicating their potential as diagnostic biomarkers of TB infection. Notably, the performance characteristics of some of these cytokine responses, including IP-10, TNF- $\alpha$, and IL-2, were similar to, or exceeded those of IFN- $\gamma$.

Importantly, our data also show that certain cytokine responses, including TNF- $\alpha$, IL1ra and IL-10, in addition to identifying TB infection, may simultaneously allow the distinction between LTBI and active TB. Further, we have shown that high levels of discriminatory accuracy can be achieved by combining these biomarkers. This potentially represents a significant advance, as current immunodiagnostic tests (i.e. TST and IGRA) are unable to make this distinction. ${ }^{5}$ From a clinical perspective, the ability to discriminate between LTBI and active TB based on a blood test alone, which can provide a result within two days, would be an important advantage, as this would allow clinicians to make timely management decisions, rather than having to wait for culture results, which can take several weeks.

Several recent studies have aimed to identify biomarkers of TB infection, and some have also attempted to identify biomarkers that differ between cases with LTBI and active TB. Harari et al., who used multi-color flow cytometry to analyze responses to stimulation with RD1 antigens (ESAT-6 and CFP-10), reported that MTB-specific CD4+ T cells producing only TNF- $\alpha$ are the hallmark of active TB, while 
polyfunctional CD4+ T cells producing IFN- $\gamma$, IL-2 and TNF- $\alpha$ are characteristic of $\mathrm{LTBI}^{23}$ Based on their findings, the authors suggested measurement of singlepositive TNF- $\alpha+$ CD4+ T cells could be used in the diagnostic setting to distinguish between both infection states. However, the high cost of flow cytometry and the need for highly-trained personnel limit its usefulness in resource-limited, high TB prevalence settings where better TB diagnostics are needed most. Our data suggest that phenotypic analysis of the cellular origin of TNF- $\alpha$ may not be necessary, and that cytokine measurement in supernatant, which could be achieved with much simpler methods, is likely to be sufficient.

A number of studies have previously highlighted the diagnostic potential of IP-10 (CXCL10). ${ }^{24-30}$ In agreement with our findings, those studies showed that MTBspecific IP-10 responses in TB-infected individuals are of greater magnitude than IFN- $\gamma$ responses, and that this biomarker lacks the ability to distinguish between LTBI and active TB. ${ }^{24-28}$ This is not surprising as IP-10 production in polymorphonuclear neutrophils and monocytes is primarily induced by IFN- $\gamma$ that also lacks this discriminatory ability (as reflected by IGRA lacking this ability). ${ }^{31}$ MTB-specific IP10 responses likely represent an amplified read-out of IFN- $\gamma$ responses, meaning they differ quantitatively, but not qualitatively.

In our study, IL-2 responses had greater sensitivity and specificity than IFN- $\gamma$ responses for distinguishing between TB-uninfected and TB-infected individuals. Animal models show that IL-2 plays an important role in the anti-mycobacterial host immune response, ${ }^{32,33}$ but few studies have investigated the diagnostic potential of MTB-specific IL-2 responses. ${ }^{25,26,34-39}$ Similar to our findings, two of these studies 
reported that RD1 antigen-induced IL-2 responses differ between TB-uninfected and TB-infected individuals, but not between LTBI and active TB. ${ }^{26,36}$ Interestingly, data from one study using ELISpot assays suggested that combining the measurement of IFN- $\gamma$ responses with IL-2 responses results in increased sensitivity for detecting TB infection. ${ }^{37}$ However, ELISpot assays are labor-intensive and difficult to integrate into a routine diagnostic laboratory setting. Our data show that measuring IL-2 in supernatants from whole blood assays is a suitable, more practicable alternative.

Few studies have investigated MTB-specific IL-1ra responses as a diagnostic tool. ${ }^{26}$, ${ }^{40,41}$ Similar to our findings, one study found that RD1 antigen-induced IL-1ra responses were significantly higher in active TB than in LTBI. ${ }^{26}$ However, there was a substantial overlap between the IL-1 ra responses in both groups, suggesting that a categorical separation between infection states based on this biomarker alone would be difficult. Interestingly, we found that while there was considerable overlap between the magnitude of IL-1ra responses in LTBI and active TB cases when RD1 antigens were used for stimulation, there was very little overlap when PPD was used. The likely explanation for this is that PPD-stimulation resulted in several-fold higher IL-1ra responses in cases with active TB compared with RD1 antigen-stimulation (Figure 1), thereby resulting in greater differences between the two groups.

We also found that combining cytokine biomarkers resulted in accurate discrimination between LTBI and active TB. The combination of TNF- $\alpha$ and IL-1ra responses correctly classified $95.5 \%$ of cases, while the combination of TNF- $\alpha$ and IL-10 responses resulted in correct classification of all cases. The concept of combining two or more cytokine biomarkers to improve the distinction between 
infection states has been explored previously. Frahm et al. used a model based on MCP-1 and IL-15 responses, but only achieved $86.4 \%$ correct classification with this approach. ${ }^{26}$ Wang et al. used an IL-2/IFN- $\gamma$ ratio, which achieved a sensitivity and specificity of $77.2 \%$ and $87.2 \%$, respectively. ${ }^{39}$ A study by Sutherland et al. that compared anti-mycobacterial cytokine responses in patients with LTBI (defined as TST-positive individuals) with active TB patients reported that in PPD-stimulated samples a combination of TNF- $\alpha$, IL-12(p40) and IL-13 responses correctly classified $81 \%$ of cases. ${ }^{42}$

This study has also produced interesting data in relation to patients with discordance, who remain a significant management dilemma in clinical practice. ${ }^{5,7,10,11}$ It has been postulated that a TST+/IGRA- discordant result constellation is predominately the result of false-positive TST results, primarily resulting from prior BCG vaccination. However, while BCG vaccination can produce false-positive TST results due to crossreactivity of antigens present in PPD and antigens produced by BCG vaccine strains, solid evidence to support that this accounts for the majority of cases with discordance is lacking. Notably, the results of a meta-analysis, involving more than 200,000 children in 24 studies, suggest that only $8.5 \%$ of individuals BCG-vaccinated in infancy develop a false-positive TST (defined as $\geq 10 \mathrm{~mm}$ induration), ${ }^{43}$ indicating that BCG vaccination alone is unlikely to account for the large proportions of discordance reported in most pediatric IGRA studies. ${ }^{44-46}$ In our study, we observed multiple statistically significant differences between the cytokine responses in the uninfected group and the common discordance group. Importantly, these differences were also detected in samples stimulated with ESAT-6 and CFP-10, which cannot be explained by antigenic cross-reactivity, as both peptides are absent from all BCG 
vaccine strains. ${ }^{8}$ However, there was also considerable overlap between the responses observed in both groups, with some patients with common discordance showing no response to antigenic stimulation, highlighting that these patients are likely a heterogeneous group comprising both TB-infected and TB-uninfected individuals.

For all cytokines identified as potential TB biomarkers in this study there are convincing data indicating that they play an important role in the anti-mycobacterial host immune response. The central role of TNF- $\alpha$ in the human immune response to mycobacterial infections is undisputed. ${ }^{15}$ Multiple studies have shown that patients treated with TNF- $\alpha$ inhibitors for autoimmune conditions are at significant risk of TB progression. ${ }^{47,48}$ The importance of IL-1ra in the anti-mycobacterial immune response, particularly related to granuloma formation, has been extensively documented in animal models. ${ }^{49}$ Recent reports of TB reactivation in patients treated with monoclonal IL-1ra further highlight the importance of this cytokine in this setting. ${ }^{48}$. Infection of murine macrophages with MTB has been shown to result in upregulation of MIP-1 $\beta$ expression. ${ }^{50}$ Also, progression of TB disease is associated with increased MIP-1 $\beta$ expression in murine lung tissue. ${ }^{50}$ In vitro studies in humans have shown that infection of macrophages with MTB results in increased production of MIP-1 $\beta$, which suppresses intracellular growth of MTB. ${ }^{51}$ IL-13 is a key cytokine in the alternative activation of macrophages, which is associated with macrophage fusion and granuloma formation, a critical event in mycobacterial infections. ${ }^{52,53}$

The main limitation of this study is the inclusion of a limited number of patients with active TB, a limitation shared by many other studies in this area. $23,26,27,29,34,38$ Nonetheless the differences in cytokine responses were sufficiently large to enable the 
detection of statistical differences between the diagnostic groups. An important strength of this study is the use of unambiguous diagnostic groups in the analyses. Many previous immunodiagnostic studies have included patients with uncertain TB infection status (eg solely based on TST results) or uncertain active TB cases (eg 'possible' and 'probable TB' cases based on clinical features alone), and therefore have an inherent risk for data contamination to occur. One limitation of all diagnostic biomarker studies is that cut-offs and performance characteristics are based on the data from the study population, thus potentially overestimating their performance. Our study population did not include cases at the most 'severe' end of the disease spectrum (i.e. miliary TB or TB meningitis); therefore the performance of our cytokine biomarkers in these patients remains uncertain. In addition, the majority of children with active TB were older than 10 years of age and it is therefore uncertain whether their performance is equally robust in infants and young children.

Consequently, further evaluation of these biomarkers is required in larger cohorts with a broad range of disease manifestations. Further studies in both children and in adults are currently ongoing.

In conclusion, our study shows that a number of MTB-specific cytokine responses, including IP-10, TNF- $\alpha$, IL-1ra, IL-2, IL-13, and MIP-1 $\beta$, allow the distinction between individuals infected with TB and those without TB infection. Importantly, some of these biomarkers had better performance characteristics than IFN- $\gamma$. In addition, we have identified biomarkers that distinguish between LTBI and active TB potentially with high levels of accuracy. Incorporation of these biomarkers in future immunodiagnostic assays for TB could result in substantial gains in assay sensitivity, 
and may allow the distinction between LTBI and active TB based on a blood test alone.

\section{ACKNOWLEDGEMENTS}

The authors thank the Victorian Department of Health TB Control Team, in particular Lynne Brown and Lucy Cosentino, for their help with recruitment, and Dr David Leslie and Dr Norbert Ryan at the Victorian Infectious Diseases Reference Laboratory for their assistance with the QuantiFERON-TB Gold assays. We also thank the children and parents who kindly agreed to participate in this study. 
Table 1. Criteria for categorization of study participants

\begin{tabular}{|c|c|c|}
\hline Diagnostic category & $\begin{array}{c}\text { TST } \\
\text { induration }\end{array}$ & $\begin{array}{c}\text { QFT-GIT } \\
\text { assay result }\end{array}$ \\
\hline Uninfected & $0 \mathrm{~mm}$ & Negative \\
\hline Probable uninfected & $1-4 \mathrm{~mm}$ & Negative \\
\hline Possible discordance & $5-9 \mathrm{~mm}$ & Negative \\
\hline Common discordance & $\geq 10 \mathrm{~mm}$ & Negative \\
\hline LTBI & $\geq 10 \mathrm{~mm}$ & Positive \\
\hline Active TB & * & * \\
\hline Reverse discordance & $<10 \mathrm{~mm}$ & Positive \\
\hline
\end{tabular}


Table 2. Demographic and other details of study participants in each diagnostic category

\begin{tabular}{|c|c|c|c|c|c|}
\hline & $\begin{array}{l}\text { Total cohort } \\
(n=140)\end{array}$ & $\begin{array}{l}\text { Uninfected } \\
(n=75)\end{array}$ & $\begin{array}{c}\text { Common } \\
\text { discordance } \\
(n=28)\end{array}$ & $\begin{array}{l}\text { LTBI } \\
(n=16)\end{array}$ & $\begin{array}{l}\text { Active TB } \\
(n=6)\end{array}$ \\
\hline Median age, years (IQR) & $\begin{array}{c}8.3 \\
(3.7-12.8)\end{array}$ & $\begin{array}{c}6.3 \\
(2.8-10.9)\end{array}$ & $\begin{array}{c}12.1 \\
(6.0-14.5)\end{array}$ & $\begin{array}{c}11.6 \\
(6.0-14.2)\end{array}$ & $\begin{array}{c}15.0 \\
(12.1-16.2)\end{array}$ \\
\hline \multicolumn{6}{|l|}{ Ethnic origin, no. (\%) } \\
\hline Africa & $60(42.8)$ & $31(41.3)$ & $9(32.1)$ & $10(62.5)$ & $5(83.3)$ \\
\hline Asia & $53(37.9)$ & $24(32.0)$ & $13(46.4)$ & $5(31.3)$ & $1(16.7)$ \\
\hline Middle East & $9(6.4)$ & $5(6.7)$ & $4(14.3)$ & 0 & 0 \\
\hline Australia/New Zealand & $18(12.9)$ & $15(20)$ & $2(7.1)$ & $1(6.3)$ & 0 \\
\hline \multicolumn{6}{|l|}{ Country of birth, no. (\%) } \\
\hline Africa & $41(29.3)$ & $14(18.7)$ & $8(28.6)$ & $10(62.5)$ & $5(83.3)$ \\
\hline Asia & $29(20.7)$ & $10(13.3)$ & $7(25.0)$ & $5(31.3)$ & $1(16.7)$ \\
\hline Middle East & $9(6.4)$ & $4(5.3)$ & $4(14.3)$ & 0 & 0 \\
\hline Australia/New Zealand & $59(42.1)$ & $47(62.7)$ & $8(28.6)$ & $1(6.3)$ & 0 \\
\hline Europe & $2(1.4)$ & 0 & $1(3.6)$ & 0 & 0 \\
\hline Migration background $^{*}$, no. (\%) & $81(57.9)$ & $28(37.3)$ & $20(71.4)$ & $15(93.8)$ & $6(100)$ \\
\hline $\begin{array}{l}\text { Time of migration to Australia*, } \\
\text { months (IQR) }\end{array}$ & $\begin{array}{c}8.0 \\
(3.5-36.0)\end{array}$ & $\begin{array}{c}5.5 \\
(2.0-33.0)\end{array}$ & $\begin{array}{c}17.0 \\
(6.0-36.0)\end{array}$ & $\begin{array}{c}7.0 \\
(4.0-36.0)\end{array}$ & $\begin{array}{c}21.0 \\
(3.0-69.0)\end{array}$ \\
\hline \multicolumn{6}{|l|}{ BCG vaccination history, no. (\%) } \\
\hline Yes & $75(53.6)$ & $23(30.7)$ & $21(75.0)$ & $14(87.5)$ & $5(83.3)$ \\
\hline No & $58(42.4)$ & $49(65.3)$ & $4(14.2)$ & $1(6.3)$ & $1(16.7)$ \\
\hline Unknown & $7(5.0)$ & $3(4.0)$ & $3(10.7)$ & $1(6.3)$ & 0 \\
\hline \multicolumn{6}{|l|}{ BCG scar, no. (\%) } \\
\hline Yes & $67(47.9)$ & $22(29.3)$ & $18(64.3)$ & $12(75.0)$ & $5(83.3)$ \\
\hline No & $73(52.1)$ & $53(70.7)$ & $10(35.7)$ & $4(25.0)$ & $1(16.7)$ \\
\hline \multicolumn{6}{|l|}{ Known TB contact, no. (\%) } \\
\hline Yes & $89(63.6)$ & $54(72.0)$ & $14(50.0)$ & $8(50.0)$ & $1(16.7)$ \\
\hline No & $51(36.4)$ & $21(28.0)$ & $14(50.0)$ & $8(50.0)$ & $5(83.3)$ \\
\hline \multicolumn{6}{|l|}{ Type of TB contact, no. (\%) } \\
\hline Parent & $34(24.3)$ & $14(18.6)$ & $9(32.1)$ & $4(25.0)$ & $1(16.7)$ \\
\hline Other household member & $33(23.6)$ & $23(30.7)$ & $3(10.7)$ & $3(18.8)$ & 0 \\
\hline Other contact & $22(15.7)$ & $17(22.7)$ & $2(7.1)$ & $1(6.3)$ & 0 \\
\hline
\end{tabular}


Table 3. Comparisons of median cytokine responses (p-values) from the data shown in figure 1. Statistically significant p-values are highlighted in bold.

\begin{tabular}{|c|c|c|c|c|c|c|c|c|}
\hline Stimulant & Cytokine & $\begin{array}{c}\text { Kruskal } \\
\text { Wallis } \\
\text { p-value }\end{array}$ & $\begin{array}{l}\text { Uninfected } \\
\text { vs. } \\
\text { CD } \\
\end{array}$ & $\begin{array}{l}\text { Uninfected } \\
\text { vs. } \\
\text { LTBI }\end{array}$ & $\begin{array}{l}\text { Uninfected } \\
\text { vs. } \\
\text { Active TB }\end{array}$ & $\begin{array}{c}\text { CD } \\
\text { vs. } \\
\text { LTBI }\end{array}$ & $\begin{array}{c}\text { CD } \\
\text { vs. } \\
\text { Active TB } \\
\end{array}$ & $\begin{array}{c}\text { LTBI } \\
\text { vs. } \\
\text { Active TB } \\
\end{array}$ \\
\hline \multirow[t]{17}{*}{ ESAT-6 } & IFN-Y & $<0.0001$ & 0.0147 & $<0.0001^{*}$ & $<0.0001^{*}$ & $0.0001^{*}$ & $0.0008^{*}$ & 0.3020 \\
\hline & IP-10 & $<0.0001$ & 0.0026 & $<0.0001^{*}$ & $<0.0001^{*}$ & $<0.0001^{*}$ & $0.0007^{*}$ & 0.8828 \\
\hline & TNF- $\alpha$ & $<0.0001$ & 0.0504 & $<0.0001^{*}$ & $<0.0001^{*}$ & $<0.0001^{*}$ & $0.0004^{*}$ & 0.0183 \\
\hline & IL-1ra & $<0.0001$ & 0.2925 & $0.0005^{*}$ & $<0.0001^{*}$ & 0.0180 & $0.0007^{*}$ & 0.0183 \\
\hline & IL-2 & $<0.0001$ & $<0.0001^{*}$ & $<0.0001^{*}$ & $<0.0001^{*}$ & $<0.0001^{*}$ & $0.0010^{*}$ & 0.5070 \\
\hline & IL-6 & 0.0642 & - & - & - & - & - & - \\
\hline & IL-8 & 0.7564 & - & - & - & - & - & - \\
\hline & IL-10 & 0.1042 & - & - & - & - & - & - \\
\hline & IL-12(p40) & 0.0061 & 0.0080 & 0.0255 & 0.0540 & 0.6258 & 0.2433 & 0.3451 \\
\hline & IL-13 & $<0.0001$ & 0.0269 & $<0.0001^{*}$ & $<0.0001^{*}$ & 0.0127 & $0.0006^{*}$ & 0.0650 \\
\hline & IL-15 & 0.4083 & - & - & - & - & - & - \\
\hline & IL-17 & 0.1647 & - & - & - & - & - & - \\
\hline & GM-CSF & $<0.0001$ & 0.6012 & $<0.0001^{*}$ & 0.0058 & $<0.0001^{*}$ & 0.0129 & 0.7124 \\
\hline & MCP-1 & 0.1701 & - & - & - & - & - & - \\
\hline & MCP-3 & 0.1038 & - & - & - & - & - & - \\
\hline & MIP-1 $\beta$ & $<0.0001$ & 0.1883 & $<0.0001^{*}$ & $<0.0001^{*}$ & $0.0005^{*}$ & $0.0006^{*}$ & 0.0900 \\
\hline & RANTES & 0.3249 & - & - & - & - & - & - \\
\hline \multirow[t]{17}{*}{ CFP-10 } & IFN-Y & $<0.0001$ & 0.1588 & $<0.0001^{*}$ & $<0.0001^{*}$ & 0.0128 & $0.0011^{*}$ & 0.0900 \\
\hline & IP-10 & $<0.0001$ & 0.2630 & $<0.0001^{*}$ & $<0.0001^{*}$ & $0.0013^{*}$ & 0.0018 & 0.6058 \\
\hline & TNF- $\alpha$ & $<0.0001$ & 0.2908 & $<0.0001^{*}$ & $<0.0001^{*}$ & 0.0029 & $0.0005^{*}$ & 0.0121 \\
\hline & IL-1ra & $<0.0001$ & 0.4653 & $0.0013^{*}$ & $0.0003^{*}$ & 0.0338 & 0.0025 & 0.1048 \\
\hline & IL-2 & $<0.0001$ & 0.0202 & $<0.0001^{*}$ & $<0.0001^{*}$ & $0.0007^{*}$ & 0.0021 & 0.4174 \\
\hline & IL-6 & 0.1354 & - & - & - & - & - & - \\
\hline & IL-8 & 0.8776 & - & - & - & - & - & - \\
\hline & IL-10 & 0.0367 & 0.0279 & 0.0250 & 0.2635 & 0.7325 & 0.8037 & 0.9412 \\
\hline & IL-12(p40) & 0.1895 & - & - & - & - & - & - \\
\hline & IL-13 & $<0.0001$ & 0.0556 & 0.0066 & $<0.0001^{*}$ & 0.1368 & $0.0004^{*}$ & 0.0765 \\
\hline & IL-15 & 0.9146 & - & - & - & - & - & - \\
\hline & IL-17 & 0.4539 & - & - & - & - & - & - \\
\hline & GM-CSF & 0.0013 & 0.4064 & $0.0012^{*}$ & 0.0104 & 0.0192 & 0.0377 & 0.7681 \\
\hline & MCP-1 & 0.1643 & - & - & - & - & - & - \\
\hline & MCP-3 & 0.0155 & 0.0149 & 0.0120 & 0.2948 & 0.5310 & 1 & 0.9105 \\
\hline & MIP-1 $\beta$ & $<0.0001$ & 0.4630 & 0.0041 & $<0.0001^{*}$ & 0.0404 & 0.0018 & 0.1404 \\
\hline & RANTES & 0.1390 & - & - & - & - & - & - \\
\hline \multirow[t]{17}{*}{$\overline{P P D}$} & IFN-Y & $<0.0001$ & $<0.0001^{*}$ & $<0.0001^{*}$ & $<0.0001^{*}$ & 0.0832 & 0.0025 & 0.1845 \\
\hline & IP-10 & $<0.0001$ & $<0.0001^{*}$ & $<0.0001^{*}$ & $0.0007^{*}$ & 0.2134 & 0.5877 & 0.0270 \\
\hline & TNF- $\alpha$ & $<0.0001$ & $<0.0001^{*}$ & $<0.0001^{*}$ & $<0.0001^{*}$ & 0.0180 & $0.0016^{*}$ & 0.0553 \\
\hline & IL-1ra & 0.0040 & 0.0154 & 0.6843 & 0.0044 & 0.0570 & 0.3203 & 0.0032 \\
\hline & IL-2 & $<0.0001$ & $<0.0001^{*}$ & $<0.0001^{*}$ & $<0.0001^{*}$ & 0.0043 & 0.0025 & 0.4610 \\
\hline & IL-6 & $<0.0001$ & $<0.0001^{*}$ & $<0.0001^{*}$ & $0.0001^{*}$ & 0.5747 & 0.0100 & 0.0122 \\
\hline & IL-8 & 0.0719 & - & - & - & - & - & - \\
\hline & IL-10 & 0.0007 & 0.3737 & 0.0022 & 0.0058 & 0.0790 & 0.0239 & $0.0004^{*}$ \\
\hline & IL-12(p40) & $<0.0001$ & $<0.0001^{*}$ & $0.0002^{*}$ & $<0.0001^{*}$ & 0.3602 & 0.0377 & 0.5070 \\
\hline & IL-13 & 0.0003 & $0.0007^{*}$ & 0.0061 & 0.0173 & 0.8073 & 0.8922 & 0.3763 \\
\hline & IL-15 & 0.2734 & - & - & - & - & - & - \\
\hline & IL-17 & 0.3771 & - & - & - & - & - & - \\
\hline & GM-CSF & $<0.0001$ & $<0.0001^{*}$ & $<0.0001^{*}$ & $0.0002^{*}$ & 0.4068 & 0.1245 & 0.4610 \\
\hline & MCP-1 & 0.4549 & - & - & - & - & - & - \\
\hline & MCP-3 & 0.2129 & - & - & - & - & - & - \\
\hline & MIP-1 $\beta$ & $<0.0001$ & $0.0004^{*}$ & $0.0002^{*}$ & $0.0024^{*}$ & 0.3667 & 0.3907 & 0.7681 \\
\hline & RANTES & 0.3126 & - & - & - & - & - & - \\
\hline
\end{tabular}


Table 4. Results of the receiver operating characteristic analyses of the seven mycobacteria-specific cytokine responses with the potential ability to discriminate between TB-uninfected and TB-infected individuals

\begin{tabular}{|c|c|c|c|c|c|c|c|c|c|c|c|c|c|c|c|c|c|c|c|c|c|}
\hline & \multicolumn{3}{|c|}{ IFN- $\gamma$} & \multicolumn{3}{|c|}{ IP-10 } & \multicolumn{3}{|c|}{ TNF- $\alpha$} & \multicolumn{3}{|c|}{ IL-1ra } & \multicolumn{3}{|c|}{ IL-2 } & \multicolumn{3}{|c|}{ IL-13 } & \multicolumn{3}{|c|}{ MIP-1 $\beta$} \\
\hline & $\begin{array}{l}\text { cut- } \\
\text { off }\end{array}$ & $\begin{array}{c}\text { sens. } \\
(\%)\end{array}$ & $\begin{array}{c}\text { spec. } \\
(\%)\end{array}$ & $\begin{array}{l}\text { cut- } \\
\text { off }\end{array}$ & $\begin{array}{c}\text { sens. } \\
(\%)\end{array}$ & $\begin{array}{c}\text { spec. } \\
(\%)\end{array}$ & $\begin{array}{l}\text { cut- } \\
\text { off }\end{array}$ & $\begin{array}{c}\text { sens. } \\
(\%)\end{array}$ & $\begin{array}{c}\text { spec. } \\
(\%)\end{array}$ & $\begin{array}{l}\text { cut- } \\
\text { off }\end{array}$ & $\begin{array}{c}\text { sens. } \\
(\%)\end{array}$ & $\begin{array}{c}\text { spec. } \\
(\%)\end{array}$ & $\begin{array}{l}\text { cut- } \\
\text { off }\end{array}$ & $\begin{array}{c}\text { sens. } \\
(\%)\end{array}$ & $\begin{array}{c}\text { spec. } \\
(\%)\end{array}$ & $\begin{array}{l}\text { cut- } \\
\text { off }\end{array}$ & $\begin{array}{c}\text { sens. } \\
(\%)\end{array}$ & $\begin{array}{c}\text { spec. } \\
(\%)\end{array}$ & $\begin{array}{l}\text { cut- } \\
\text { off }\end{array}$ & $\begin{array}{c}\text { sens. } \\
(\%)\end{array}$ & $\begin{array}{c}\text { spec. } \\
(\%)\end{array}$ \\
\hline ESAT-6 & 10.2 & 90.9 & 97.3 & 10820.0 & 95.5 & 96.0 & 5.99 & 95.5 & 88.0 & -28.5 & 81.8 & 69.3 & 16.7 & 95.5 & 97.3 & 0.32 & 77.3 & 89.3 & 158.6 & 90.9 & 70.7 \\
\hline CFP-10 & 0.8 & 81.8 & 89.3 & 2204.0 & 86.4 & 93.3 & 1.9 & 86.4 & 85.3 & -23.6 & 77.3 & 78.7 & 4.7 & 90.9 & 94.7 & 0.05 & 63.6 & 86.7 & 50.2 & 77.3 & 68.0 \\
\hline PPD & 659.4 & 95.5 & 97.3 & 46571.0 & 95.5 & 81.3 & 125.3 & 95.5 & 84.0 & 279.7 & 50.0 & 46.7 & 383.7 & 100.0 & 96.0 & 103.5 & 77.3 & 69.3 & 9618.0 & 81.8 & 60.0 \\
\hline
\end{tabular}

All cut-offs are in pg/ml. Bold figures indicate that both sensitivity and specificity exceed $80 \%$. Abbreviations: sens.: sensitivity; spec.: specificity. 
Figure 1. Box plot with Tukey whiskers showing background-corrected cytokine concentrations in uninfected participants (white) and participants with common discordance (yellow), LTBI (orange) and active TB (red) in ESAT-6 (Part A), CFP-10 (Part B) and PPD (Part C) stimulated samples. Statistical differences were analyzed using Kruskal Wallis tests; the corresponding p-values are shown at the top of each graph. The results of additional two-group comparisons are detailed in Table 3.

Figure 2. Receiver operating characteristic curves for IFN- $\gamma$, IP-10, TNF- $\alpha$, IL-1ra, IL-2, IL-13, and MIP-1 $\beta$ responses according to antigenic stimulant (ESAT-6, CFP10, PPD). Case values comprised background-corrected cytokine concentrations in participants with LTBI or active TB (TB-infected group); control values comprised cytokine concentrations in uninfected participants.

Figure 3. Background-corrected TNF- $\alpha$, IL-1 ra and IL-10 concentrations in participants with LTBI (circles) and active TB (squares) in ESAT-6, CFP-10 and PPD stimulated samples. The bars indicate the median concentrations. The dotted lines indicate the optimal cut-offs for the distinction between participants with LTBI and those with active TB. Statistical differences were analyzed using Mann-Whitney $U$ tests; the corresponding $\mathrm{p}$-values are shown above each bracket.

Figure 4. Background-corrected TNF- $\alpha$, IL-1 ra and IL-10 concentrations in uninfected participants (diamonds), participants with LTBI (circles) and active TB (squares) in PPD stimulated samples. Part A shows the combination of TNF- $\alpha / \mathrm{IL}-1 \mathrm{ra}$, part B the combination of TNF- $\alpha /$ IL-10. The dotted lines indicate the optimal cut-offs for the distinction between participants with LTBI and those with active TB (TNF- $\alpha$ : 800 pg/ml; IL-1ra: 450 pg/ml; IL-10: 100 pg/ml). 


\section{REFERENCES}

1. Dye C. Global epidemiology of tuberculosis. Lancet 2006;367(9514):938-940.

2. World Health Organisation. Global tuberculosis report 2013. Available from: http://www.whoint/tb/publications/global_report/en/.

3. Marais BJ, Gie RP, Schaaf HS, Beyers N, Donald PR, Starke JR. Childhood pulmonary tuberculosis: old wisdom and new challenges. Am J Respir Crit Care Med 2006;173:1078-1090.

4. Nicol MP, Workman L, Isaacs W, Munro J, Black F, Eley B, Boehme CC, Zemanay W, Zar HJ. Accuracy of the Xpert MTB/RIF test for the diagnosis of pulmonary tuberculosis in children admitted to hospital in Cape Town, South Africa: a descriptive study. Lancet Infect Dis 2011;11:819-824.

5. Tebruegge M, Connell T, Curtis N. Tuberculosis in children. $N$ Engl J Med $2012 ; 367: 1568$

6. Tebruegge M, Ritz N, Curtis N, Shingadia D. Diagnostic tests for childhood tuberculosis - past imperfect, present tense and future perfect? Pediatr Infect Dis $J$ 2015; in press.

7. Tebruegge M, Connell T, Ritz N, Bryant PA, Curtis N. Discordance between TSTs and IFN-gamma release assays: the role of NTM and the relevance of mycobacterial sensitins. Eur Respir J 2010;36:214-215.

8. Andersen P, Munk ME, Pollock JM, Doherty TM. Specific immune-based diagnosis of tuberculosis. Lancet 2000;356:1099-1104.

9. Sester M, Sotgiu G, Lange C, Giehl C, Girardi E, Migliori GB, Bossink A, Dheda K, Diel R, Dominguez J, et al. Interferon-gamma release assays for the diagnosis of active tuberculosis: a systematic review and meta-analysis. Eur Respir J 2011;37:100-111. 
10. Connell T, Tebruegge M, Ritz N, Curtis N. Interferon-gamma release assays for the diagnosis of tuberculosis. Pediatr Infect Dis J 2009;28:758-759.

11. Connell TG, Tebruegge M, Ritz N, Bryant P, Curtis N. The potential danger of a solely interferon-gamma release assay-based approach to testing for latent Mycobacterium tuberculosis infection in children. Thorax 2010;66:263-264.

12. Connell TG, Tebruegge M, Ritz N, Bryant PA, Leslie D, Curtis N. Indeterminate interferon-gamma release assay results in children. Pediatr Infect Dis J 2010;29:285-286.

13. Haustein T, Ridout DA, Hartley JC, Thaker U, Shingadia D, Klein NJ, Novelli V, Dixon GL. The likelihood of an indeterminate test result from a whole-blood interferon-gamma release assay for the diagnosis of Mycobacterium tuberculosis infection in children correlates with age and immune status. Pediatr Infect Dis J 2009;28:669-673.

14. Tebruegge M, de Graaf H, Sukhtankar P, Elkington P, Marshall B, Schuster H, Patel S, Faust SN. Extremes of age are associated with indeterminate QuantiFERON-TB gold assay results. J Clin Microbiol 2014;52:2694-2697.

15. Kaufmann SH. How can immunology contribute to the control of tuberculosis? Nat Rev Immunol 2001;1:20-30.

16. Ruhwald M, Ravn P. Biomarkers of latent TB infection. Expert Rev Respir Med 2009;3:387-401.

17. Clifford V, Zufferey C, Street A, Denholm J, Tebruegge M, Curtis N. Cytokine biomarkers for monitoring anti-tuberculous therapy: a systematic review. Tuberculosis (Edinb) 2015; in press. 
18. Naseer A, Naqvi S, Kampmann B. Evidence for boosting Mycobacterium tuberculosis-specific IFN-gamma responses at 6 weeks following tuberculin skin testing. Eur Respir J 2007;29:1282-1283.

19. Ritz N, Yau C, Connell TG, Tebruegge M, Leslie D, Curtis N. Absence of interferon-gamma release assay conversion following tuberculin skin testing. Int J Tuberc Lung Dis 2011;15:767-769.

20. Globan M, Fyfe J. Mycobacterium tuberculosis complex. In: Schuller M, Sloots TP, James GS, Halliday CL, Carter IWJ, editors. PCR for clinical microbiology, 1st ed. New York, NY: Springer; 2010. p. 165-170.

21. American Thoracic Society and the Centers for Disease Control and Prevention. Diagnostic standards and classification of tuberculosis in adults and children. Official statement of the American Thoracic Society and the Centers for Disease Control and Prevention. Am J Respir Crit Care Med 2000;161:1376-1395.

22. Whiting P, Rutjes AW, Reitsma JB, Bossuyt PM, Kleijnen J. The development of QUADAS: a tool for the quality assessment of studies of diagnostic accuracy included in systematic reviews. BMC Med Res Methodol 2003;3:25.

23. Harari A, Rozot V, Enders FB, Perreau M, Stalder JM, Nicod LP, Cavassini M, Calandra T, Blanchet CL, Jaton K, et al. Dominant TNF-alpha $(+)$ Mycobacterium tuberculosis-specific CD4(+) T cell responses discriminate between latent infection and active disease. Nat Med 2011;17:372-376.

24. Alsleben N, Ruhwald M, Russmann H, Marx FM, Wahn U, Magdorf K. Interferon-gamma inducible protein 10 as a biomarker for active tuberculosis and latent tuberculosis infection in children: a case-control study. Scand J Infect Dis 2012;44:256-262. 
25. Armand M, Chhor V, de Lauzanne A, Guerin-El Khourouj V, Pedron B, Jeljeli M, Gressens P, Faye A, Sterkers G. Cytokine responses to quantiferon peptides in pediatric tuberculosis: A pilot study. $J$ Infect 2014;68:62-70.

26. Frahm M, Goswami ND, Owzar K, Hecker E, Mosher A, Cadogan E, Nahid P, Ferrari G, Stout JE. Discriminating between latent and active tuberculosis with multiple biomarker responses. Tuberculosis (Edinb) 2011;91:250-256.

27. Whittaker E, Gordon A, Kampmann B. Is IP-10 a better biomarker for active and latent tuberculosis in children than IFNgamma? PloS One 2008;3:e3901.

28. Yassin MA, Petrucci R, Garie KT, Harper G, Arbide I, Aschalew M, Merid Y, Kebede Z, Bawazir AA, Abuamer NM, et al. Can interferon-gamma or interferon-gamma-induced-protein-10 differentiate tuberculosis infection and disease in children of high endemic areas? PloS One 2011;6:e23733.

29. Ruhwald M, Bjerregaard-Andersen M, Rabna P, Eugen-Olsen J, Ravn P. IP-10, MCP-1, MCP-2, MCP-3, and IL-1RA hold promise as biomarkers for infection with M. tuberculosis in a whole blood based T-cell assay. BMC Res Notes 2009;2:19.

30. Ruhwald M, Bjerregaard-Andersen M, Rabna P, Kofoed K, Eugen-Olsen J, Ravn P. CXCL10/IP-10 release is induced by incubation of whole blood from tuberculosis patients with ESAT-6, CFP10 and TB7.7. Microbes Infect 2007;9:806-812.

31. Gasperini S, Marchi M, Calzetti F, Laudanna C, Vicentini L, Olsen H, Murphy M, Liao F, Farber J, Cassatella MA. Gene expression and production of the monokine induced by IFN-gamma (MIG), IFN-inducible T cell alpha chemoattractant (I-TAC), and IFN-gamma-inducible protein-10 (IP-10) chemokines by human neutrophils. J Immunol 1999;162:4928-4937. 
32. Colizzi V. In vivo and in vitro administration of interleukin 2-containing preparation reverses T-cell unresponsiveness in Mycobacterium bovis BCGinfected mice. Infect Immun 1984;45:25-28.

33. Hubbard RD, Collins FM. Immunomodulation of mouse macrophage killing of Mycobacterium avium in vitro. Infect Immun 1991;59:570-574.

34. Biselli R, Mariotti S, Sargentini V, Sauzullo I, Lastilla M, Mengoni F, Vanini V, Girardi E, Goletti D, et al. Detection of interleukin-2 in addition to interferon-gamma discriminates active tuberculosis patients, latently infected individuals, and controls. Clin Microbiol Infect 2010;16:1282-1284.

35. Casey R, Blumenkrantz D, Millington K, Montamat-Sicotte D, Kon OM, Wickremasinghe M, Bremang S, Magtoto M, Sridhar S, Connell D, et al. Enumeration of functional T-cell subsets by fluorescence-immunospot defines signatures of pathogen burden in tuberculosis. PloS One 2010;5:e15619.

36. Chiappini E, Della Bella C, Bonsignori F, Sollai S, Amedei A, Galli L, Niccolai E, Del Prete G, Singh M, D'Elios MM, et al. Potential role of M. tuberculosis specific IFN-gamma and IL-2 ELISPOT assays in discriminating children with active or latent tuberculosis. PloS One 2012;7:e46041.

37. Krummel B, Strassburg A, Ernst M, Reiling N, Eker B, Rath H, Hoerster R, Wappler W, Glaewe A, Schoellhorn V, et al. Potential role for IL-2 ELISpot in differentiating recent and remote infection in tuberculosis contact tracing. PloS One 2010;5:e11670.

38. Lighter-Fisher J, Peng CH, Tse DB. Cytokine responses to QuantiFERON(R) peptides, purified protein derivative and recombinant ESAT-6 in children with tuberculosis. Int J Tuberc Lung Dis 2010;14:1548-1555. 
39. Wang S, Diao N, Lu C, Wu J, Gao Y, Chen J, Zhou Z, Huang H, Shao L, Jin J, et al. Evaluation of the diagnostic potential of IP-10 and IL-2 as biomarkers for the diagnosis of active and latent tuberculosis in a BCG-vaccinated population. PloS One 2012;7:e51338.

40. Chegou NN, Detjen AK, Thiart L, Walters E, Mandalakas AM, Hesseling AC, Walzl G. Utility of host markers detected in Quantiferon supernatants for the diagnosis of tuberculosis in children in a high-burden setting. PloS One 2013;8:e64226.

41. Yu Y, Zhang Y, Hu S, Jin D, Chen X, Jin Q, Liu H. Different patterns of cytokines and chemokines combined with IFN-gamma production reflect Mycobacterium tuberculosis infection and disease. PloS One 2012;7:e44944.

42. Sutherland JS, de Jong BC, Jeffries DJ, Adetifa IM, Ota MO. Production of TNF-alpha, IL-12(p40) and IL-17 can discriminate between active TB disease and latent infection in a West African cohort. PloS One 2010;5:e12365.

43. Farhat M, Greenaway C, Pai M, Menzies D. False-positive tuberculin skin tests: what is the absolute effect of BCG and non-tuberculous mycobacteria? Int $J$ Tuberc Lung Dis 2006;10:1192-1204.

44. Connell TG, Ritz N, Paxton GA, Buttery JP, Curtis N, Ranganathan SC. A three-way comparison of tuberculin skin testing, QuantiFERON-TB gold and TSPOT.TB in children. PloS One 2008;3:e2624.

45. Connell TG, Curtis N, Ranganathan SC, Buttery JP. Performance of a whole blood interferon gamma assay for detecting latent infection with Mycobacterium tuberculosis in children. Thorax 2006;61:616-620.

46. Hill PC, Brookes RH, Adetifa IM, Fox A, Jackson-Sillah D, Lugos MD, Donkor SA, Marshall RJ, Howie SR, Corrah T, et al. Comparison of enzyme-linked 
immunospot assay and tuberculin skin test in healthy children exposed to Mycobacterium tuberculosis. Pediatrics 2006;117:1542-1548.

47. Wallis RS. Infectious complications of tumor necrosis factor blockade. Curr Opin Infect Dis 2009;22:403-409.

48. Singh JA, Wells GA, Christensen R, Tanjong Ghogomu E, Maxwell L, Macdonald JK, Filippini G, Skoetz N, Francis D, Lopes LC, et al. Adverse effects of biologics: a network meta-analysis and Cochrane overview. Cochrane Database Syst Rev 2011(2):CD008794.

49. Ruth JH, Bienkowski M, Warmington KS, Lincoln PM, Kunkel SL, Chensue SW. IL-1 receptor antagonist (IL-1 ra) expression, function, and cytokinemediated regulation during mycobacterial and schistosomal antigen-elicited granuloma formation. J Immunol 1996;156:2503-2509.

50. Lyadova IV, Tsiganov EN, Kapina MA, Shepelkova GS, Sosunov VV, Radaeva TV, Majorov KB, Shmitova NS, van den Ham HJ, Ganusov VV, et al. In mice, tuberculosis progression is associated with intensive inflammatory response and the accumulation of Gr-1 cells in the lungs. PloS One 2010;5:e10469.

51. Saukkonen JJ, Bazydlo B, Thomas M, Strieter RM, Keane J, Kornfeld H. Betachemokines are induced by Mycobacterium tuberculosis and inhibit its growth. Infect Immun 2002;70:1684-1693.

52. DeFife KM, Jenney CR, Colton E, Anderson JM. Cytoskeletal and adhesive structural polarizations accompany IL-13-induced human macrophage fusion. $J$ Histochem Cytochem 1999;47:65-74.

53. Gordon S. Alternative activation of macrophages. Nat Rev Immunol 2003;3:2335. 


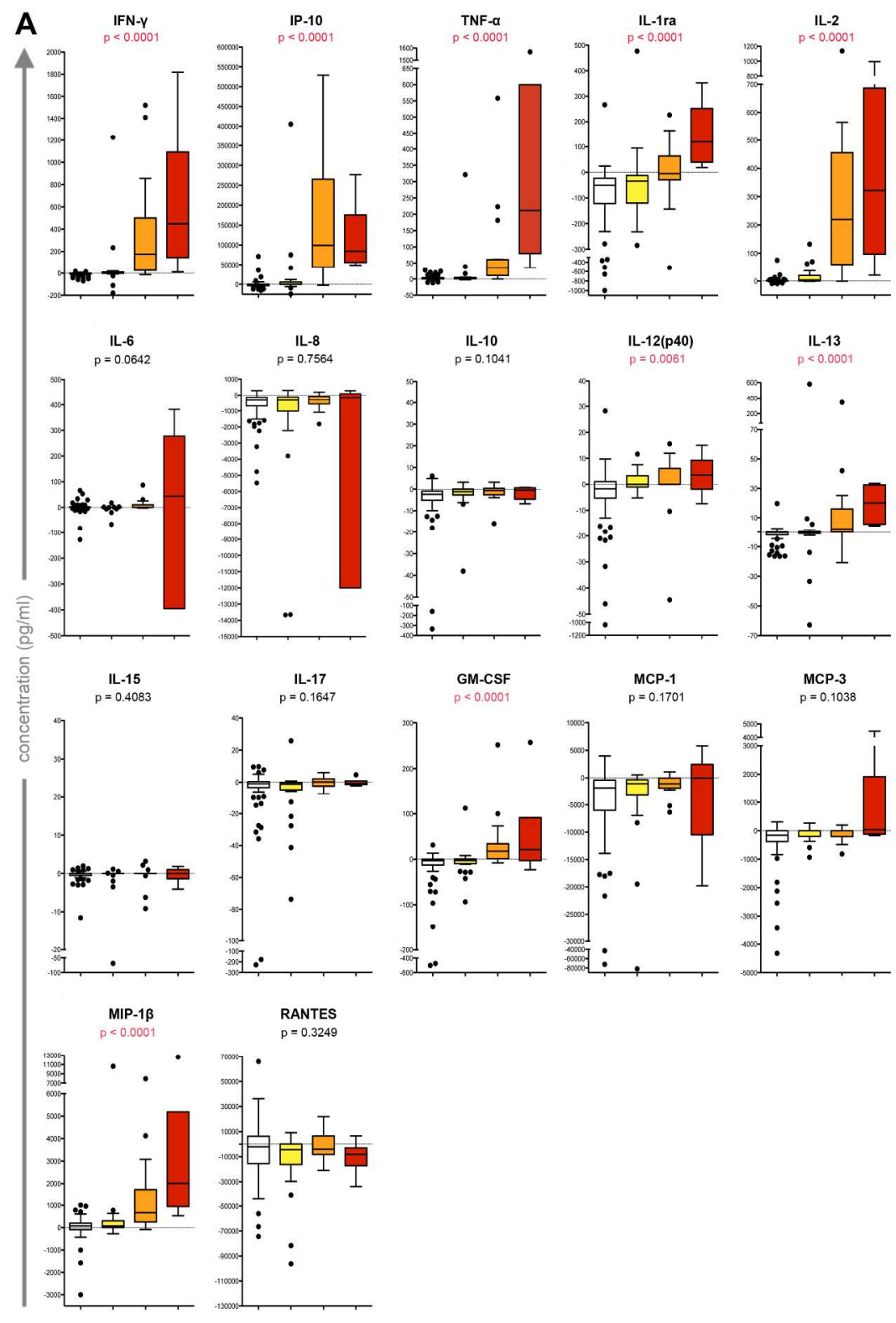

Figure 1. Box plot with Tukey whiskers showing background-corrected cytokine concentrations in uninfected participants (white) and participants with common discordance (yellow), LTBI (orange) and active TB (red) in ESAT-6 (Part A), CFP-10 (Part B) and PPD (Part C) stimulated samples. Statistical differences were analyzed using Kruskal Wallis tests; the corresponding $\mathrm{p}$-values are shown at the top of each graph. The results of additional two-group comparisons are detailed in Table 3. $186 \times 273 \mathrm{~mm}(300 \times 300$ DPI) 


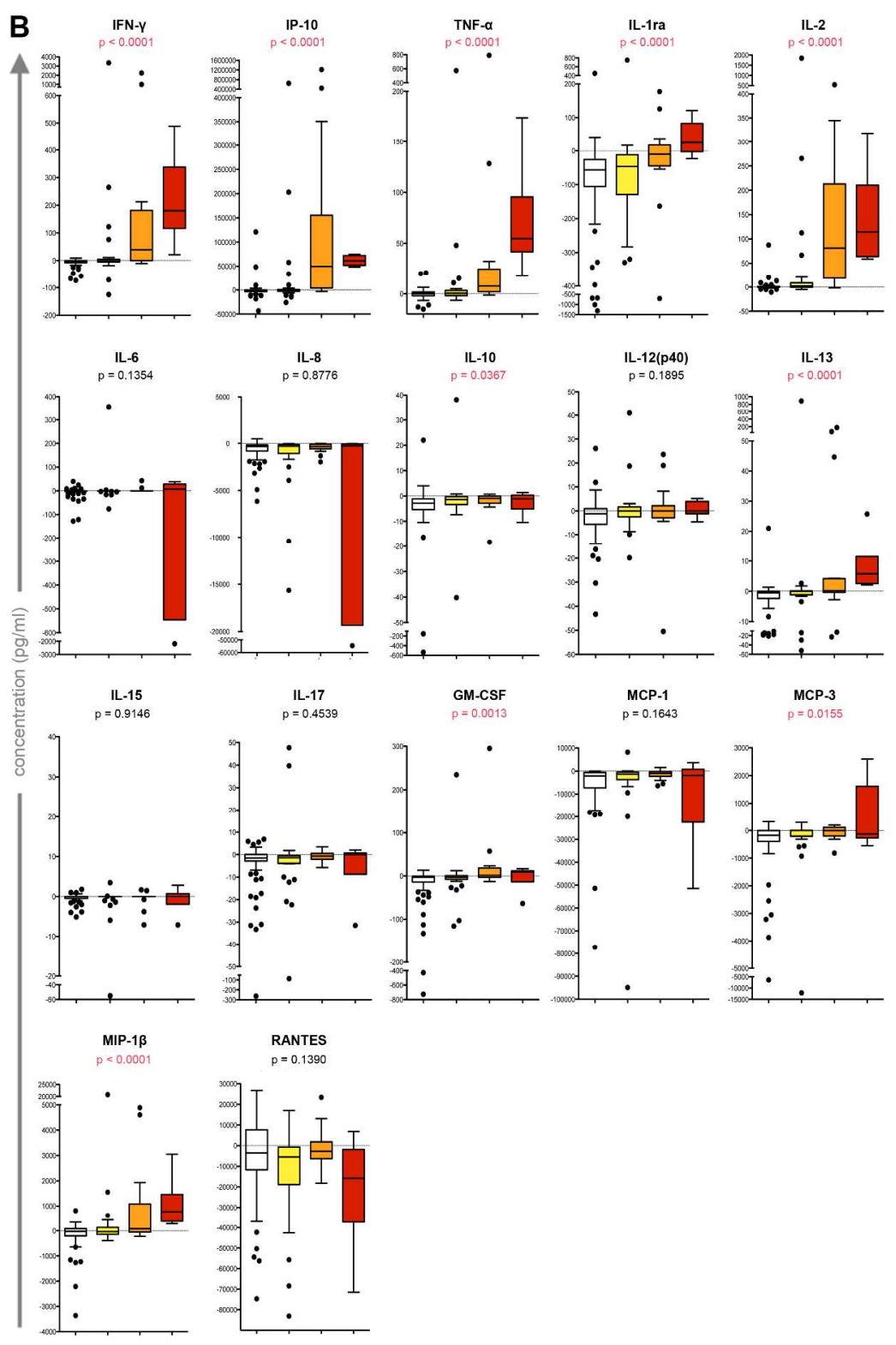

Figure 1. Box plot with Tukey whiskers showing background-corrected cytokine concentrations in uninfected participants (white) and participants with common discordance (yellow), LTBI (orange) and active TB (red) in ESAT-6 (Part A), CFP-10 (Part B) and PPD (Part C) stimulated samples. Statistical differences were analyzed using Kruskal Wallis tests; the corresponding p-values are shown at the top of each graph. The results of additional two-group comparisons are detailed in Table 3. $191 \times 284 \mathrm{~mm}(300 \times 300 \mathrm{DPI})$ 


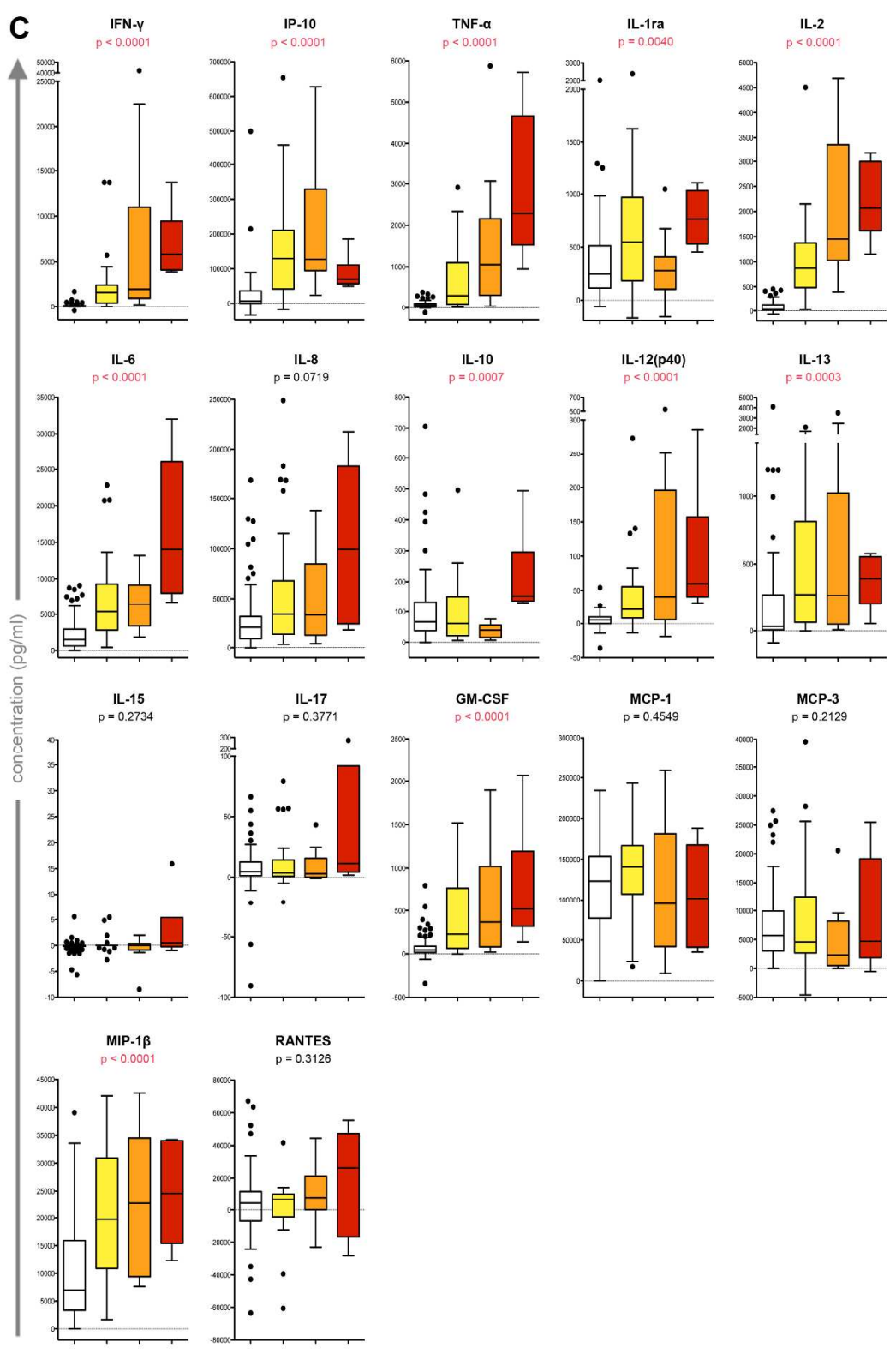

Figure 1. Box plot with Tukey whiskers showing background-corrected cytokine concentrations in uninfected participants (white) and participants with common discordance (yellow), LTBI (orange) and active TB (red) in ESAT-6 (Part A), CFP-10 (Part B) and PPD (Part C) stimulated samples. Statistical differences were analyzed using Kruskal Wallis tests; the corresponding $\mathrm{p}$-values are shown at the top of each graph. The results of additional two-group comparisons are detailed in Table 3. $190 \times 283 \mathrm{~mm}(300 \times 300$ DPI) 

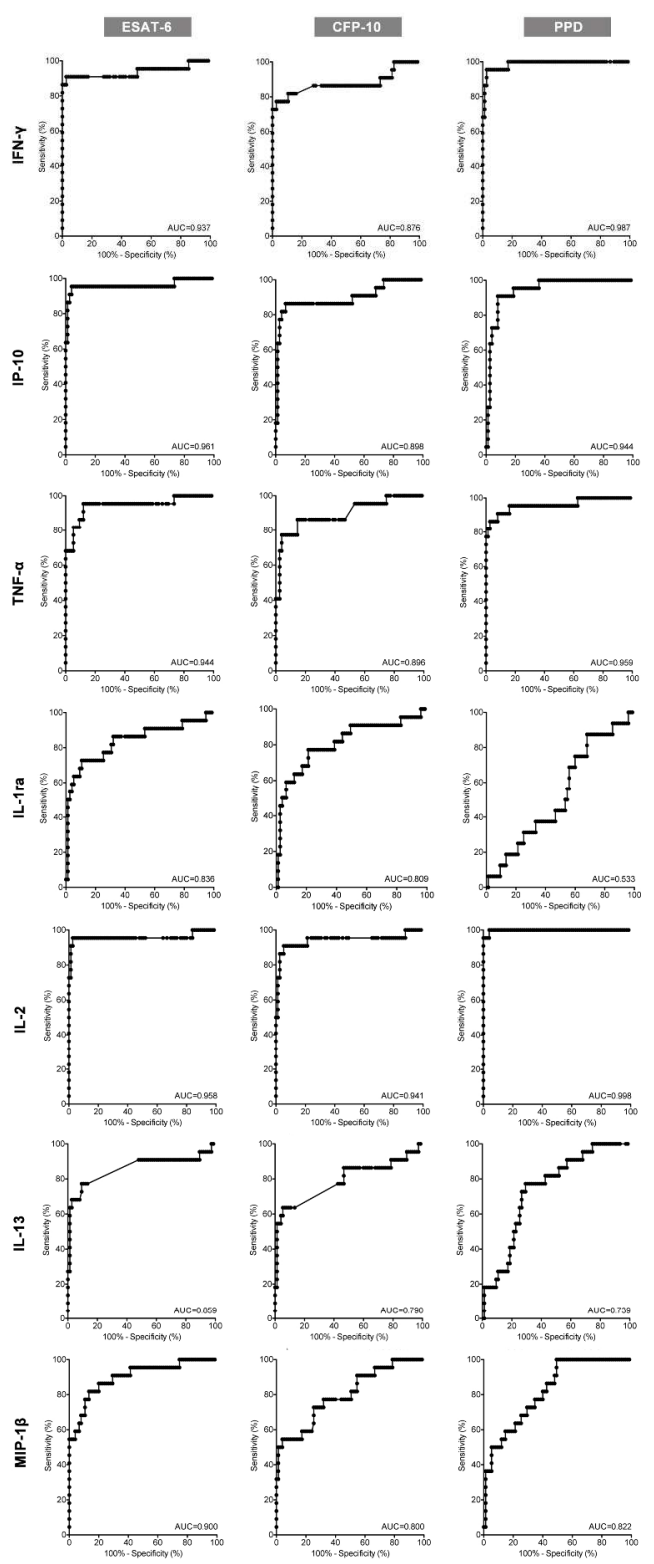

Figure 2. Receiver operating characteristic curves for IFN- $\mathrm{Y}$, IP-10, TNF-a, IL-1ra, IL-2, IL-13, and MIP-1 $\beta$ responses according to antigenic stimulant (ESAT-6, CFP-10, PPD). Case values comprised backgroundcorrected cytokine concentrations in participants with LTBI or active TB (TB-infected group); control values comprised cytokine concentrations in uninfected participants. $118 \times 285 \mathrm{~mm}(300 \times 300$ DPI $)$ 

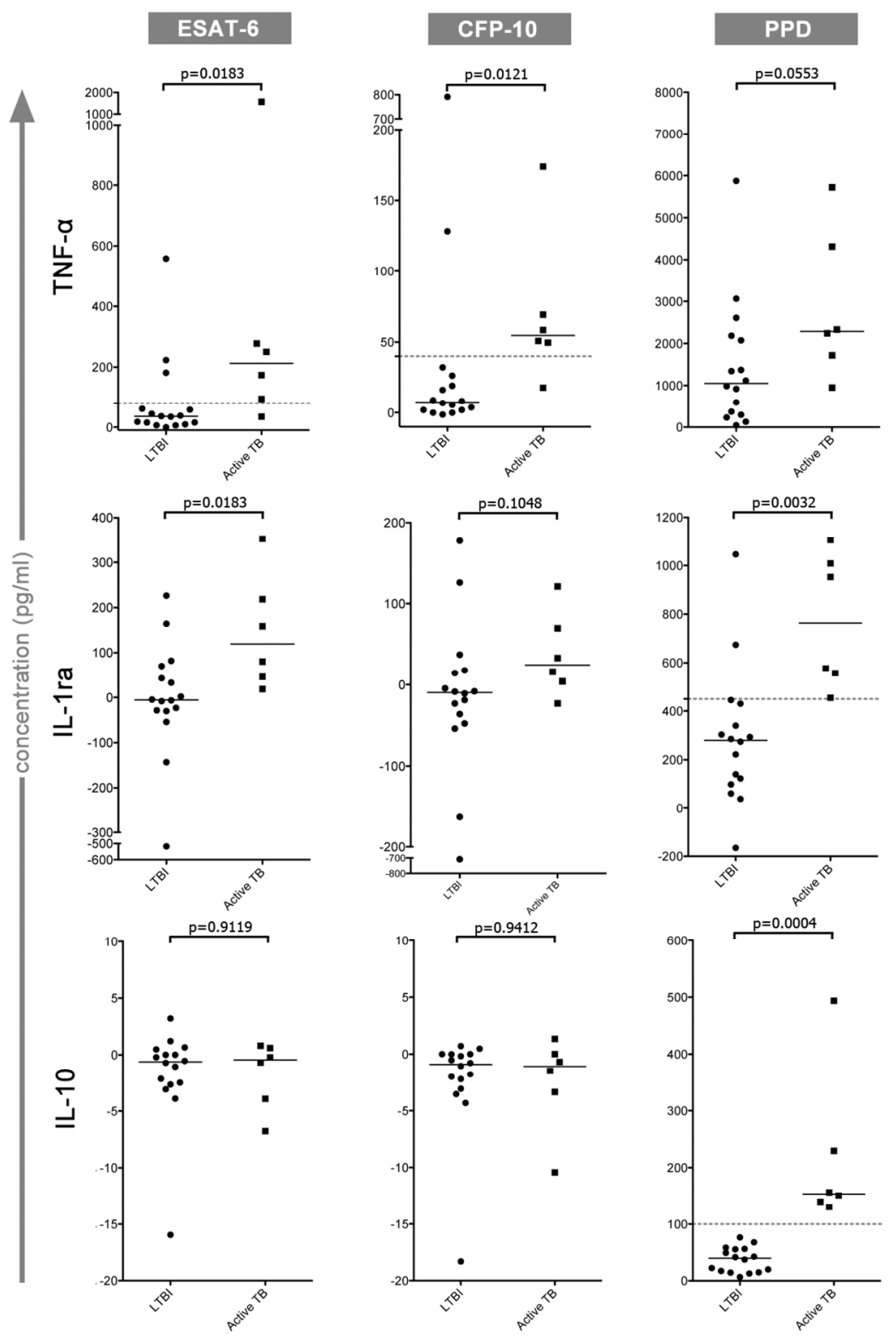

Figure 3. Background-corrected TNF-a, IL-1ra and IL-10 concentrations in participants with LTBI (circles) and active TB (squares) in ESAT-6, CFP-10 and PPD stimulated samples. The bars indicate the median concentrations. The dotted lines indicate the optimal cut-offs for the distinction between participants with LTBI and those with active TB. Statistical differences were analyzed using Mann-Whitney U tests; the corresponding $\mathrm{p}$-values are shown above each bracket. $100 \times 148 \mathrm{~mm}(300 \times 300$ DPI $)$ 


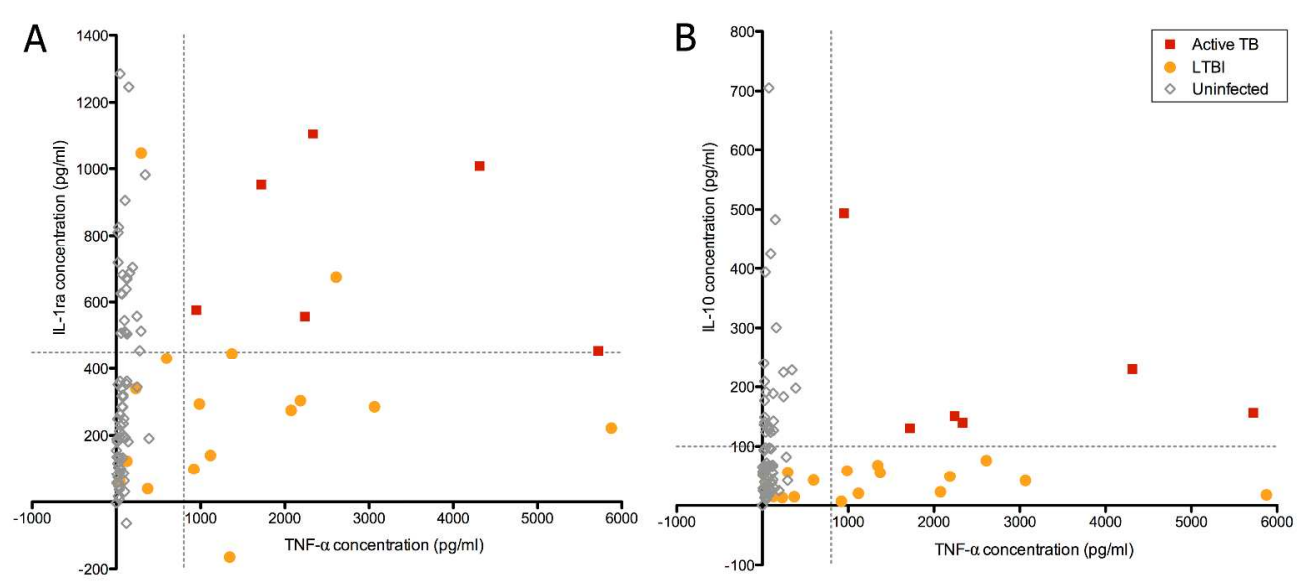

Figure 4. Background-corrected TNF-a, IL-1ra and IL-10 concentrations in uninfected participants (diamonds), participants with LTBI (circles) and active TB (squares) in PPD stimulated samples. Part A shows the combination of TNF-a/IL-1ra, part B the combination of TNF-a/IL-10. The dotted lines indicate the optimal cut-offs for the distinction between participants with LTBI and those with active TB (TNF-a: 800 $\mathrm{pg} / \mathrm{ml}$; IL-1ra: $450 \mathrm{pg} / \mathrm{ml}$; IL-10: $100 \mathrm{pg} / \mathrm{ml})$. $339 \times 149 \mathrm{~mm}(300 \times 300 \mathrm{DPI})$ 
Supplementary Table 1. Demographic details, clinical findings and investigations in study participants with active TB

\begin{tabular}{|c|c|c|c|c|c|c|}
\hline & Case 1 & Case 2 & Case 3 & Case 4 & Case 5 & Case 6 \\
\hline Age (years) & 7.3 & 13.8 & 14.7 & 15.3 & 15.9 & 17.0 \\
\hline $\begin{array}{l}\text { TB risk } \\
\text { factors }\end{array}$ & $\begin{array}{l}\text { Birth in high TB } \\
\text { prevalence } \\
\text { country } \\
\text { (Kenya) } \\
\text { Household TB } \\
\text { contact (parent } \\
\text { sputum-smear } \\
\text { positive) }\end{array}$ & $\begin{array}{l}\text { Birth in high } \\
\text { TB } \\
\text { prevalence } \\
\text { country } \\
\text { (India) }\end{array}$ & $\begin{array}{l}\text { Birth in high TB } \\
\text { prevalence } \\
\text { country } \\
\text { (Sudan) }\end{array}$ & $\begin{array}{l}\text { Birth in } \\
\text { high TB } \\
\text { prevalenc } \\
\text { e country } \\
\text { (Somalia) }\end{array}$ & $\begin{array}{l}\text { Birth in high TB } \\
\text { prevalence } \\
\text { country } \\
\text { (Somalia) }\end{array}$ & $\begin{array}{l}\text { Birth in high TB } \\
\text { prevalence } \\
\text { country } \\
\text { (Somalia) }\end{array}$ \\
\hline $\begin{array}{l}\text { History of } \\
\text { BCG } \\
\text { vaccination / } \\
\text { scar }\end{array}$ & Yes / Yes & Yes / Yes & Yes / Yes & Yes / Yes & No / No & Yes / Yes \\
\hline $\begin{array}{l}\text { Disease } \\
\text { manifestation }\end{array}$ & Pulmonary TB & $\begin{array}{l}\text { Cervical } \\
\text { lymphadeni } \\
\text { tis }\end{array}$ & $\begin{array}{l}\text { Cervical \& } \\
\text { mediastinal } \\
\text { lymphadenitis }\end{array}$ & $\begin{array}{l}\text { Chest wall } \\
\text { / } \\
\text { pleural } \\
\text { mass }\end{array}$ & Pulmonary TB & Spinal TB \\
\hline Symptoms & Chronic cough & $\begin{array}{l}\text { Persistent } \\
\text { fever, night } \\
\text { sweats, } \\
\text { weight loss, } \\
\text { enlarged, } \\
\text { non-tender } \\
\text { lymph } \\
\text { nodes } \\
\end{array}$ & $\begin{array}{l}\text { Enlarged, non- } \\
\text { tender lymph } \\
\text { nodes }\end{array}$ & $\begin{array}{l}\text { Chest wall } \\
\text { lesion }\end{array}$ & $\begin{array}{l}\text { Chronic cough, } \\
\text { persistent fever, } \\
\text { night sweats, } \\
\text { weight loss }\end{array}$ & $\begin{array}{l}\text { Weight loss, } \\
\text { back pain, } \\
\text { spinal } \\
\text { deformity }\end{array}$ \\
\hline $\begin{array}{l}\text { TST result } \\
\text { ( } \mathrm{mm} \\
\text { induration) }\end{array}$ & $\begin{array}{l}\text { Positive (25 } \\
\mathrm{mm} \text { ) }\end{array}$ & $\begin{array}{l}\text { Positive (13 } \\
\mathrm{mm} \text { ) }\end{array}$ & $\begin{array}{l}\text { Positive (14 } \\
\mathrm{mm} \text { ) }\end{array}$ & $\begin{array}{l}\text { Positive } \\
(18 \mathrm{~mm})\end{array}$ & $\begin{array}{l}\text { Positive (20 } \\
\mathrm{mm})\end{array}$ & $\begin{array}{l}\text { Positive (22 } \\
\mathrm{mm} \text { ) }\end{array}$ \\
\hline $\begin{array}{l}\text { QFT-GIT } \\
\text { result }\end{array}$ & Positive & Positive & Positive & Positive & Positive & Positive \\
\hline $\begin{array}{l}\text { Radiological } \\
\text { findings }\end{array}$ & $\begin{array}{l}\text { CXR: hilar } \\
\text { lymphadenopat } \\
\text { hy and } \\
\text { pulmonary } \\
\text { infiltrates }\end{array}$ & $\begin{array}{l}\text { CXR: } \\
\text { calcified } \\
\text { apical } \\
\text { pulmonary } \\
\text { focus }\end{array}$ & $\begin{array}{l}\text { CXR: } \\
\text { mediastinal } \\
\text { lymphadenopat } \\
\text { hy }\end{array}$ & $\begin{array}{l}\text { Chest CT: } \\
\text { pleural } \\
\text { mass with } \\
\text { extension } \\
\text { into chest } \\
\text { wall }\end{array}$ & $\begin{array}{l}\text { CXR: hilar } \\
\text { lymphadenopat } \\
\text { hy, atelectasis, } \\
\text { pulmonary } \\
\text { infiltrates } \\
\text { Chest USS: } \\
\text { pleural effusion }\end{array}$ & $\begin{array}{l}\text { CXR: hilar } \\
\text { lymphadenopat } \\
\text { hy } \\
\text { Spinal MRI: } \\
\text { vertebral body } \\
\text { destruction and } \\
\text { contrast } \\
\text { enhancement }\end{array}$ \\
\hline $\begin{array}{l}\text { Sample(s) } \\
\text { taken for } \\
\text { microbiologi } \\
\text { cal tests }\end{array}$ & $\begin{array}{l}\text { Sputum } \\
\text { samples }\end{array}$ & $\begin{array}{l}\text { Lymph } \\
\text { node tissue }\end{array}$ & $\begin{array}{l}\text { Lymph node } \\
\text { tissue }\end{array}$ & $\begin{array}{l}\text { Biopsy } \\
\text { from } \\
\text { lesion }\end{array}$ & $\begin{array}{l}\text { Sputum } \\
\text { samples }\end{array}$ & BAL \\
\hline Culture result & Negative & Positive & Positive & Positive & Negative & Negative \\
\hline PCR result & - & Positive & Positive & Positive & Negative & Negative \\
\hline Histology & - & $\begin{array}{l}\text { Caseating } \\
\text { granulomat } \\
\text { a }\end{array}$ & $\begin{array}{l}\text { Caseating } \\
\text { granulomata }\end{array}$ & $\begin{array}{l}\text { Caseating } \\
\text { granuloma } \\
\text { ta }\end{array}$ & - & - \\
\hline $\begin{array}{l}\text { Response to } \\
\text { anti-TB } \\
\text { treatment }\end{array}$ & Yes & Yes & Yes & Yes & Yes & Yes \\
\hline
\end{tabular}

